\title{
Heumann Indole Flow Chemistry Process
}

Cynthia Crifar, Fenja L. Dücker, Sacha Nguyen Thanh, Vanessa Kairouz and William D.

$$
\text { Lubell* }
$$

Department of Chemistry, University of Montreal, C.P. 6128, Succursale Centre-Ville, Montreal, Quebec H3C $3 J 7$

william.lubell@umontreal.ca

\section{Table of Contents}

Continous flow system set up

NMR spectra 


\section{Continuous flow system set-up}

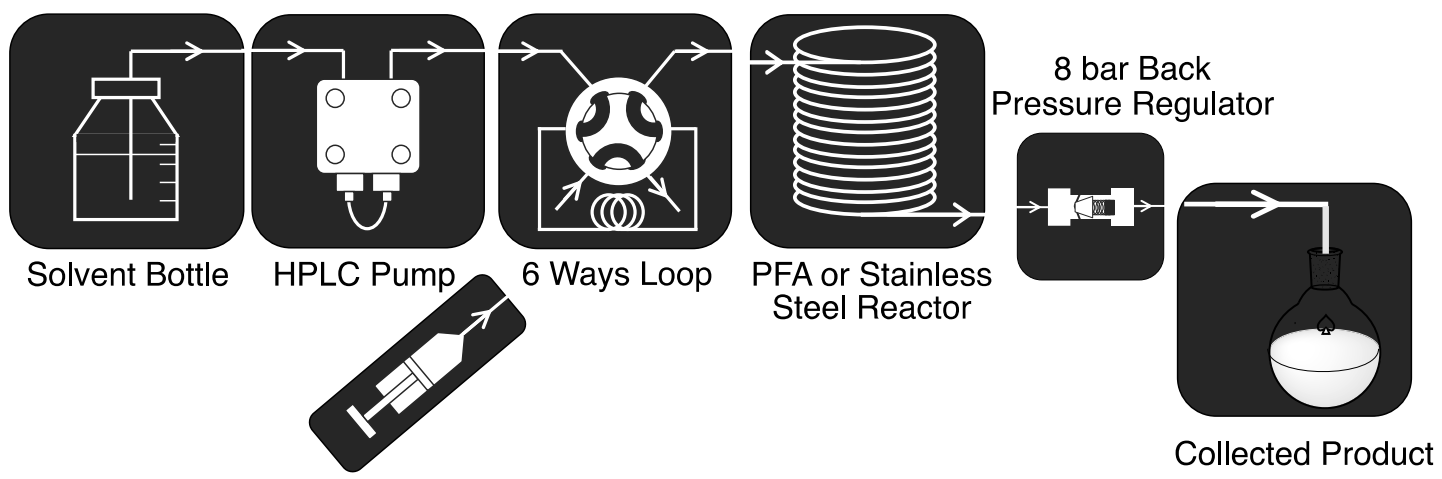

Premixed reagents

All experiments were run on a R-Series Vapourtec flow system consisting of one pump, one injection loop (from $1 \mathrm{~mL}$ to $10 \mathrm{~mL}$ ), a 5 to $10 \mathrm{~mL}$ heated reactor (PFA or Stainless Steel) and 8 bar back-pressure regulator, in that order. 
NMR Spectra
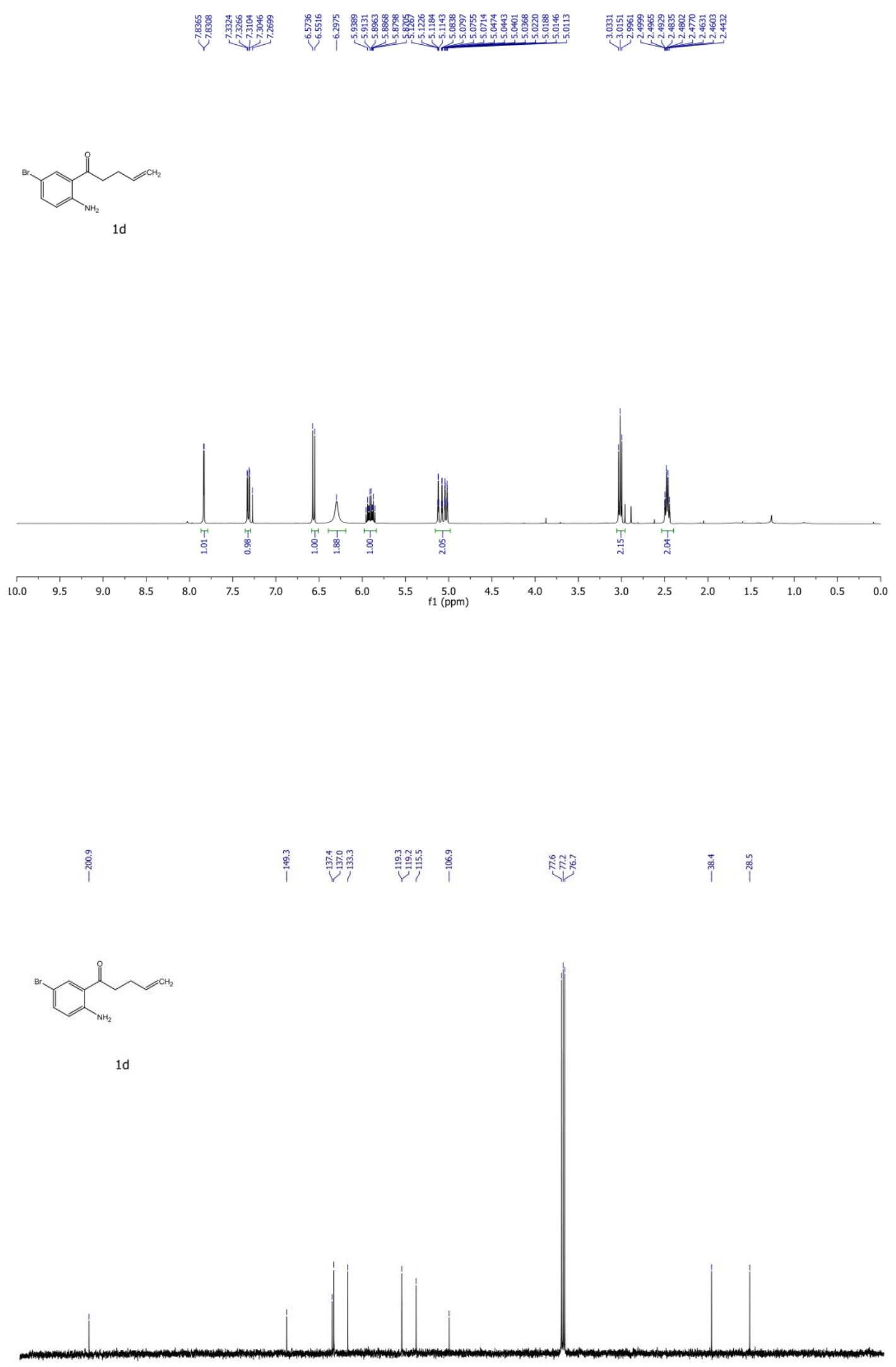

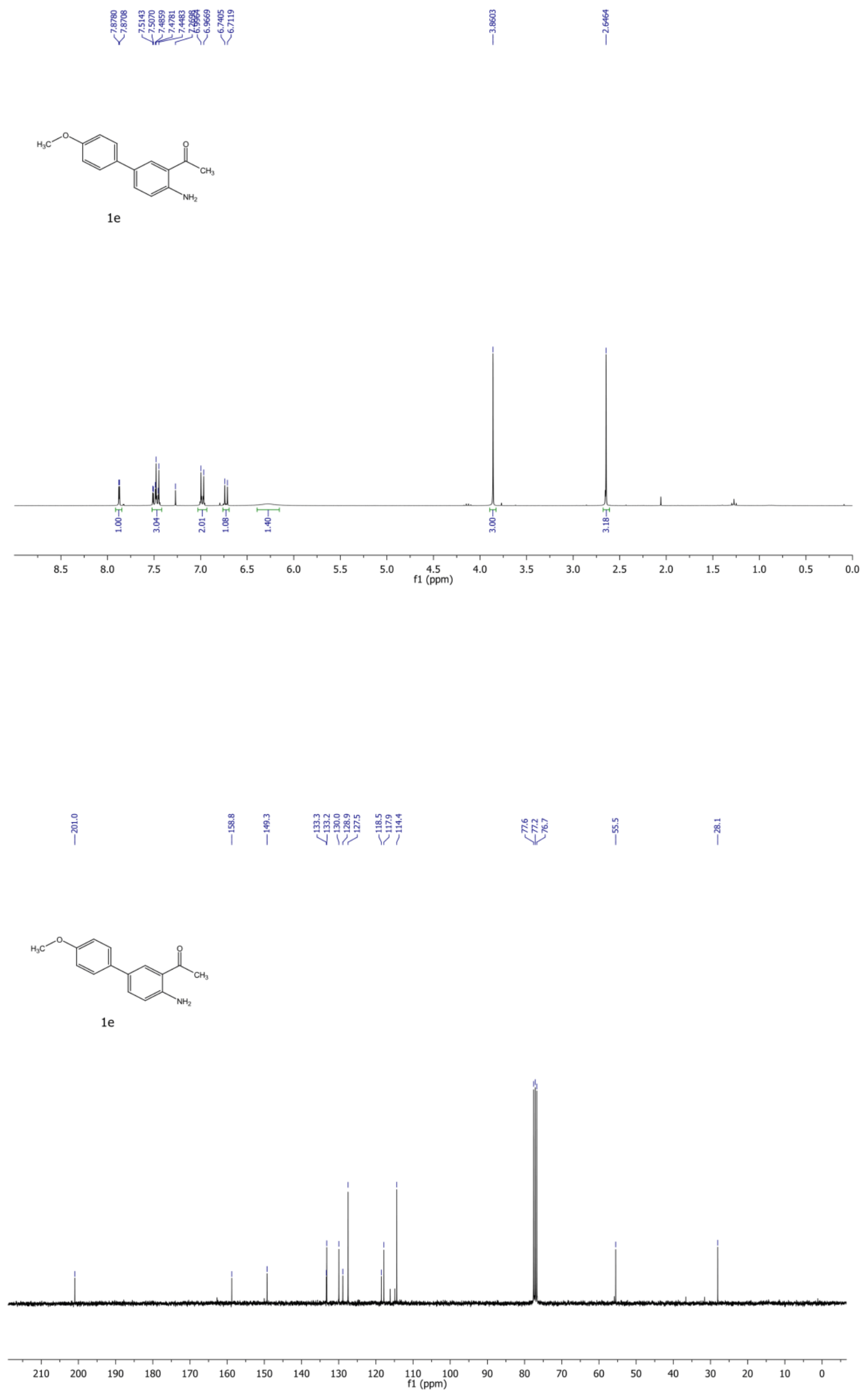


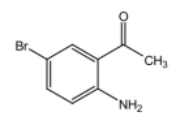

$1 \mathrm{~h}$
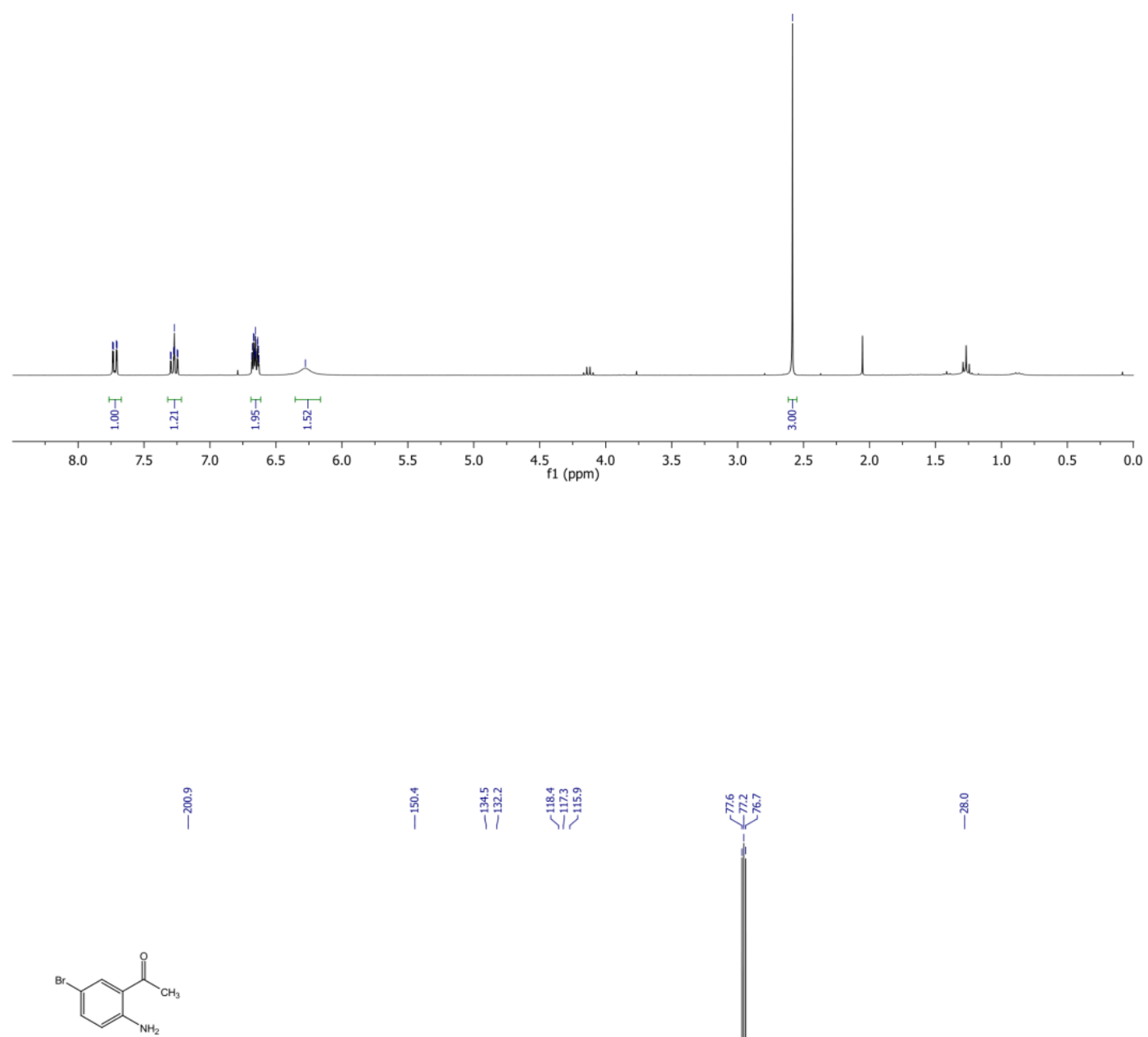

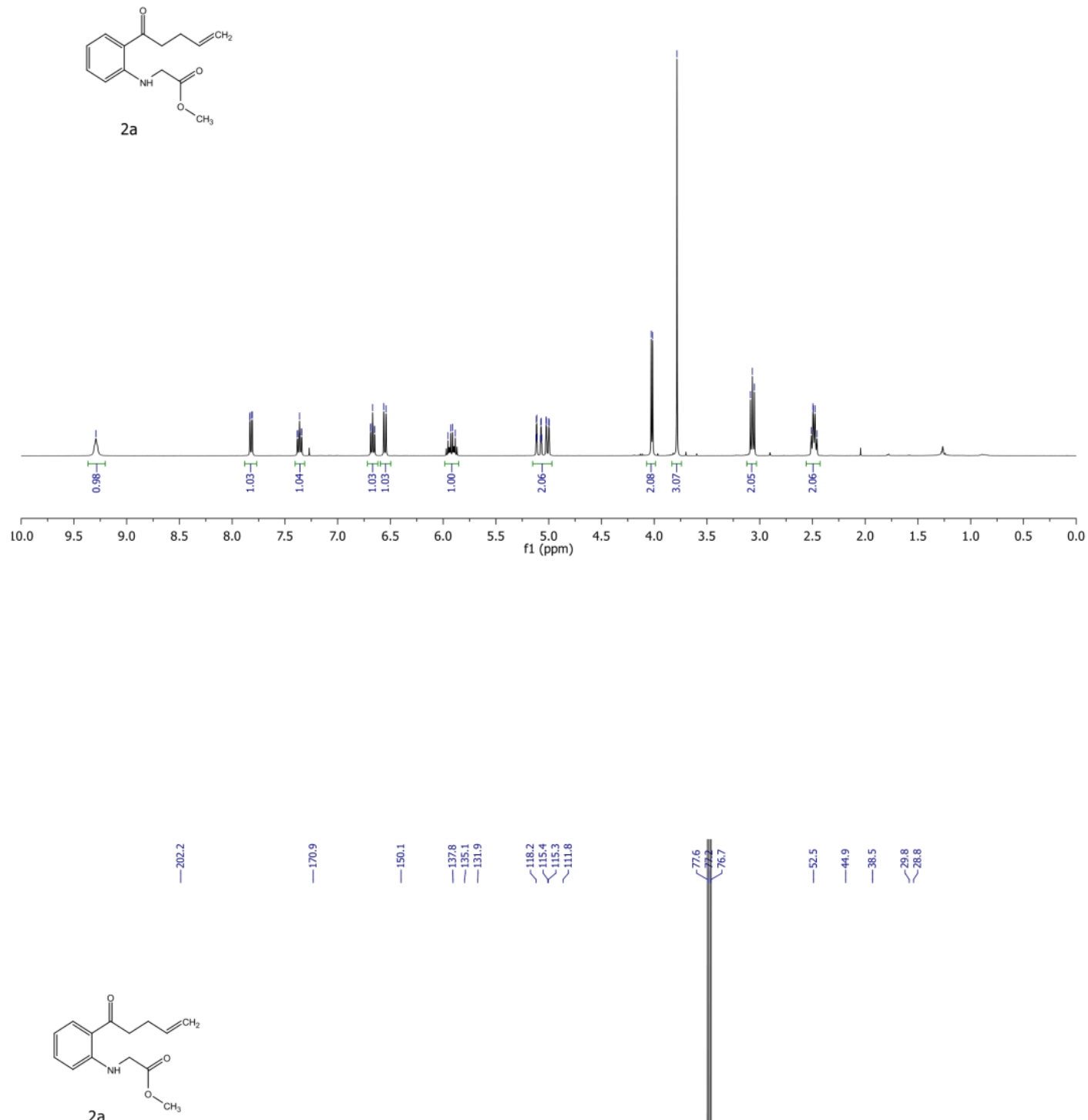

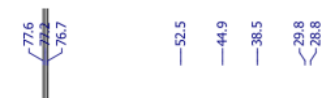

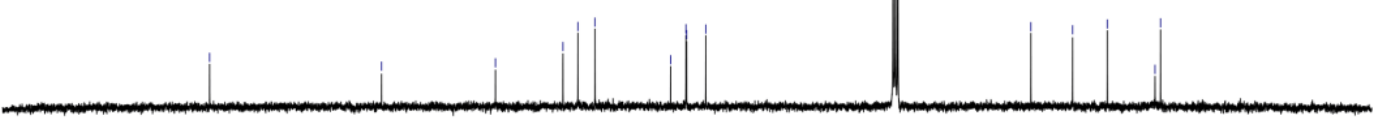




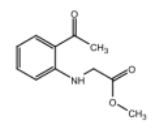

$2 b$

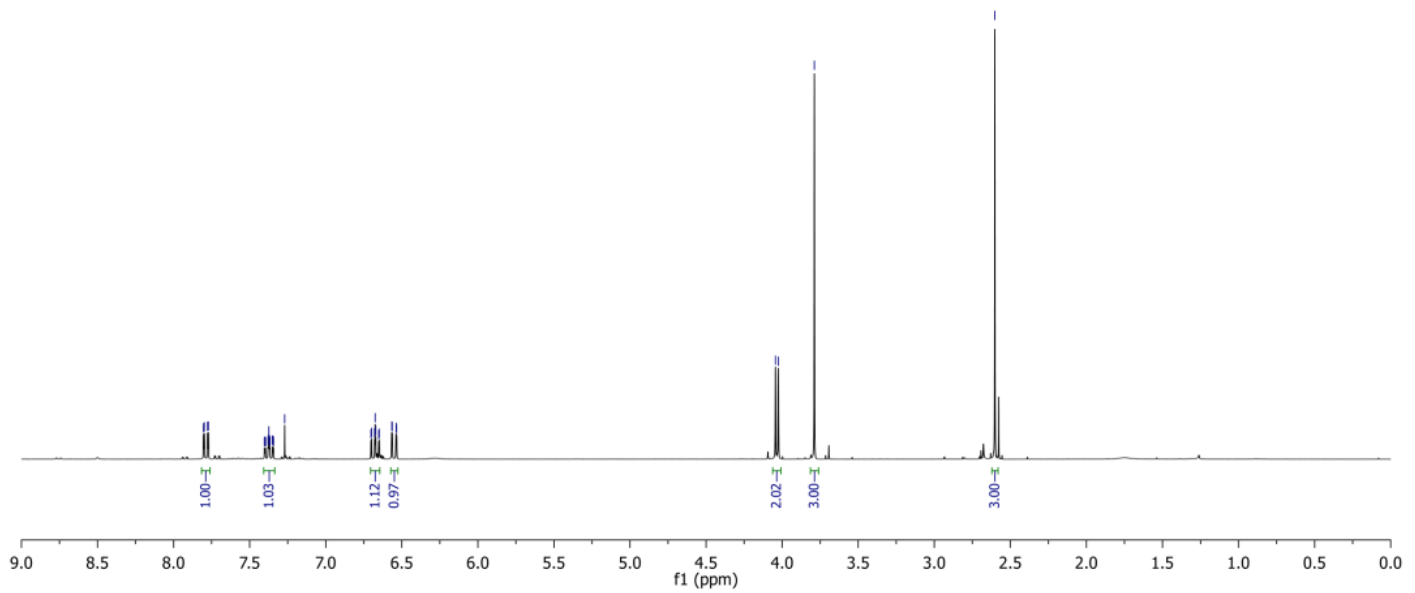

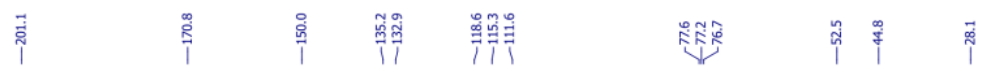

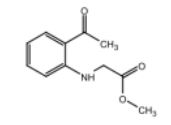

$2 b$ 

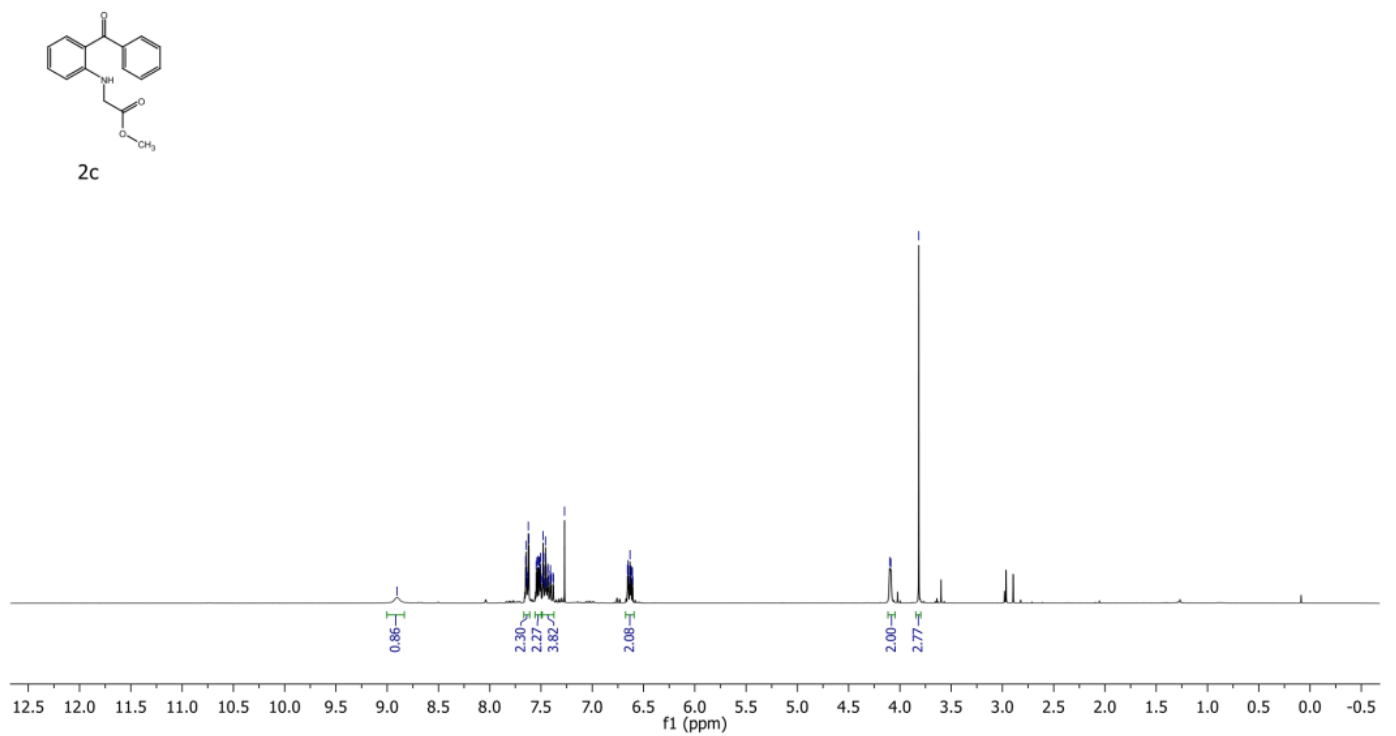

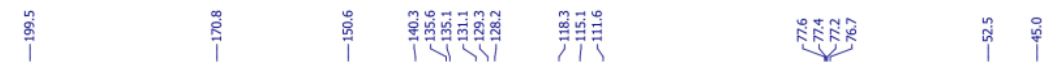

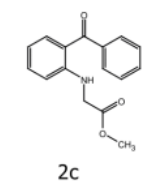

$2 c$
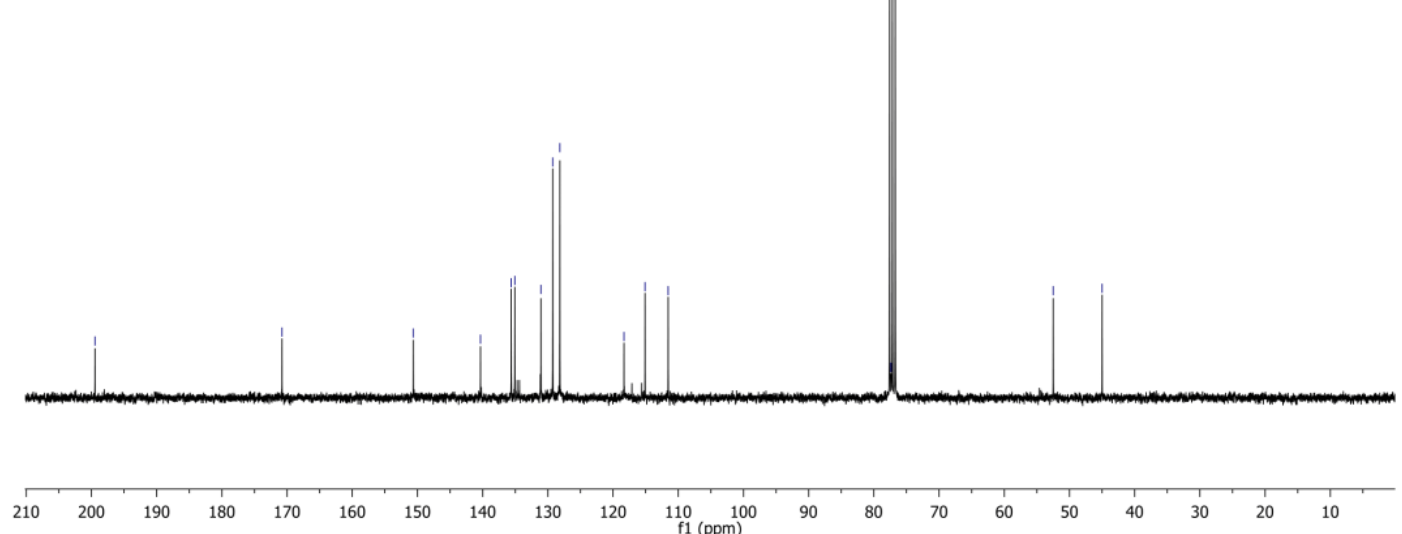

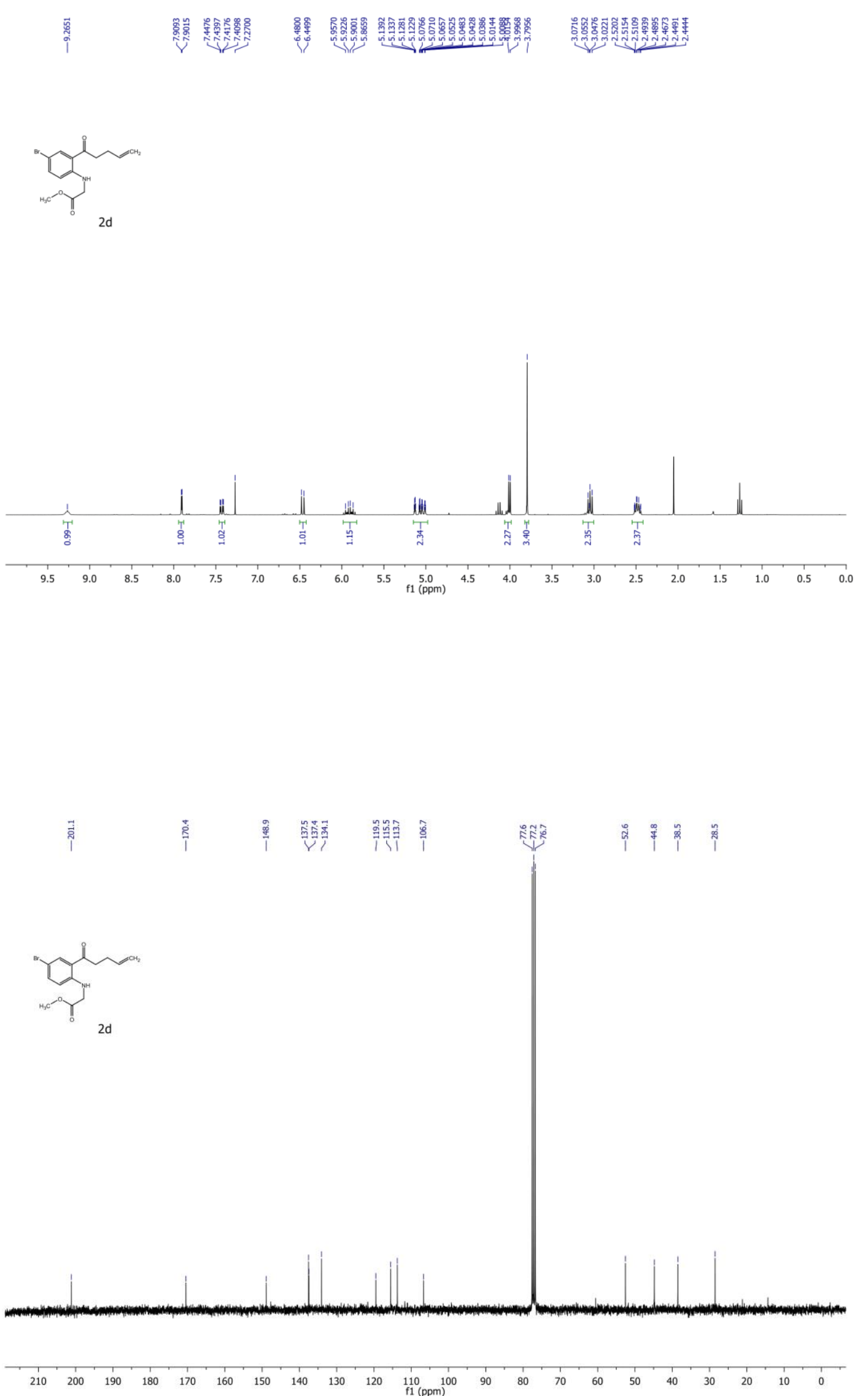


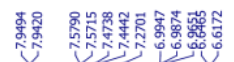

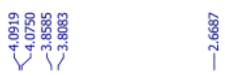

(2e

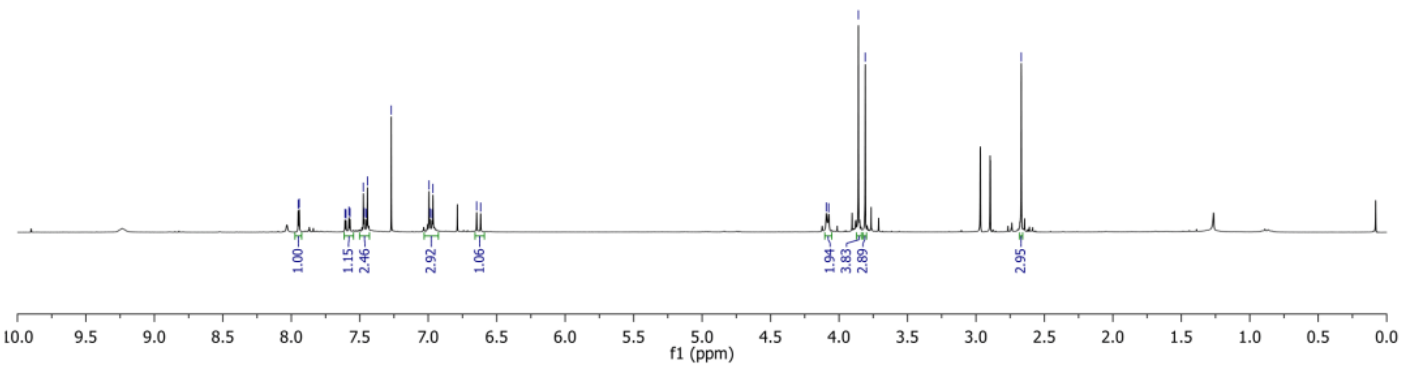

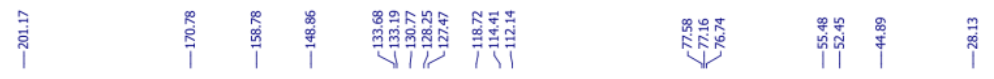

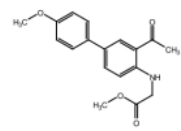

2 e

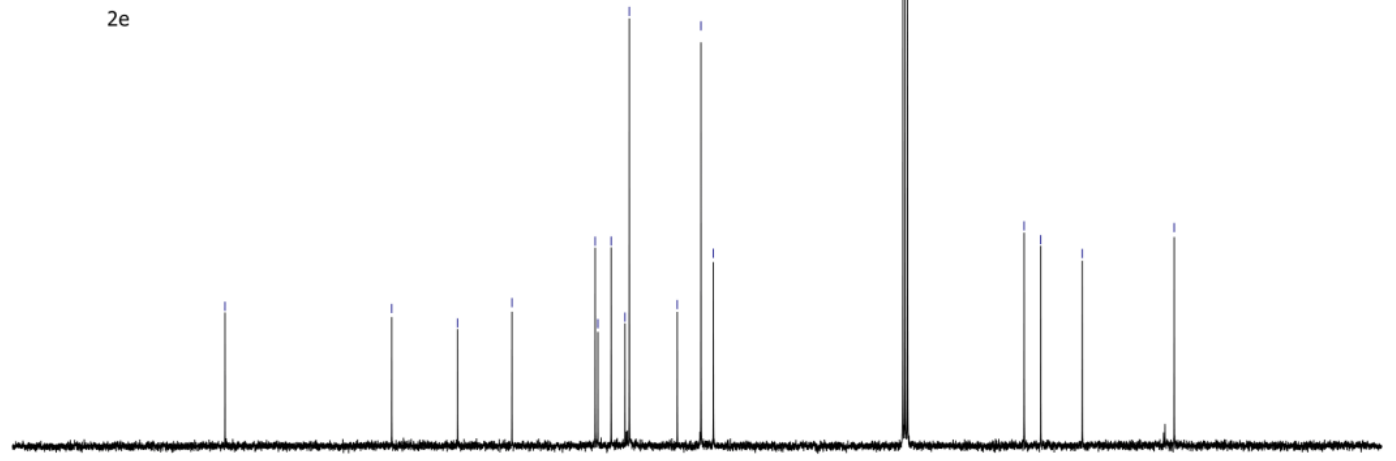

$\begin{array}{llllllllllllllllllllllllll}230 & 220 & 210 & 200 & 190 & 180 & 170 & 160 & 150 & 140 & 130 & \underset{f 1}{120}(\mathrm{ppm}) & 110 & 100 & 90 & 80 & 70 & 60 & 50 & 40 & 30 & 20 & 10 & 0 & \end{array}$ 


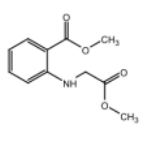

$2 f$

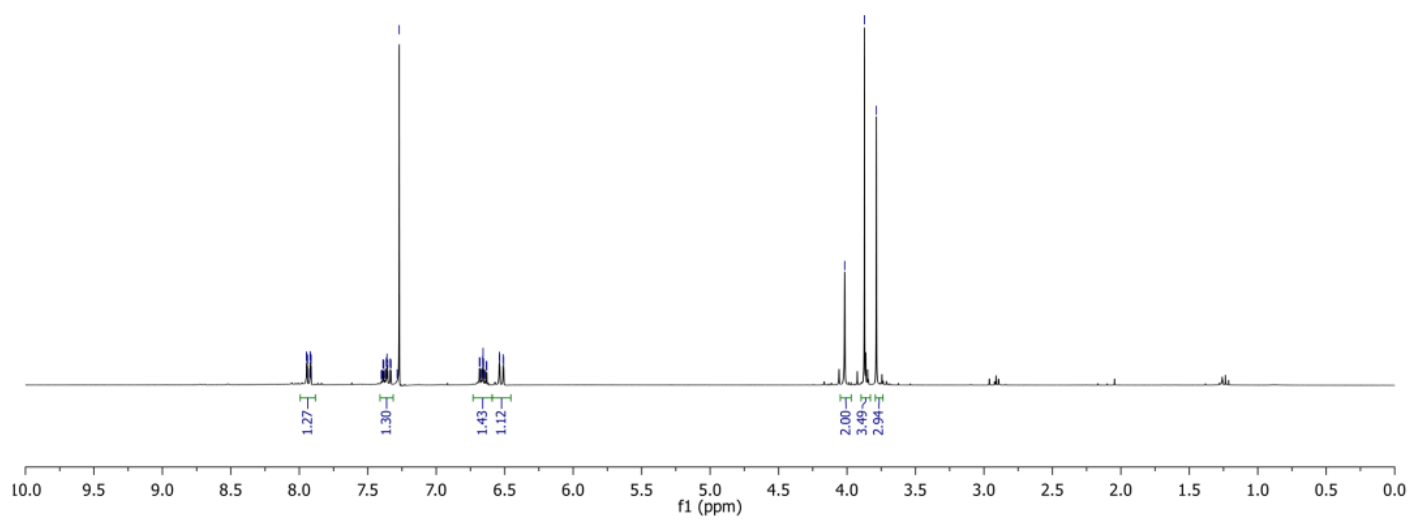

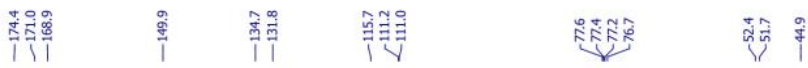
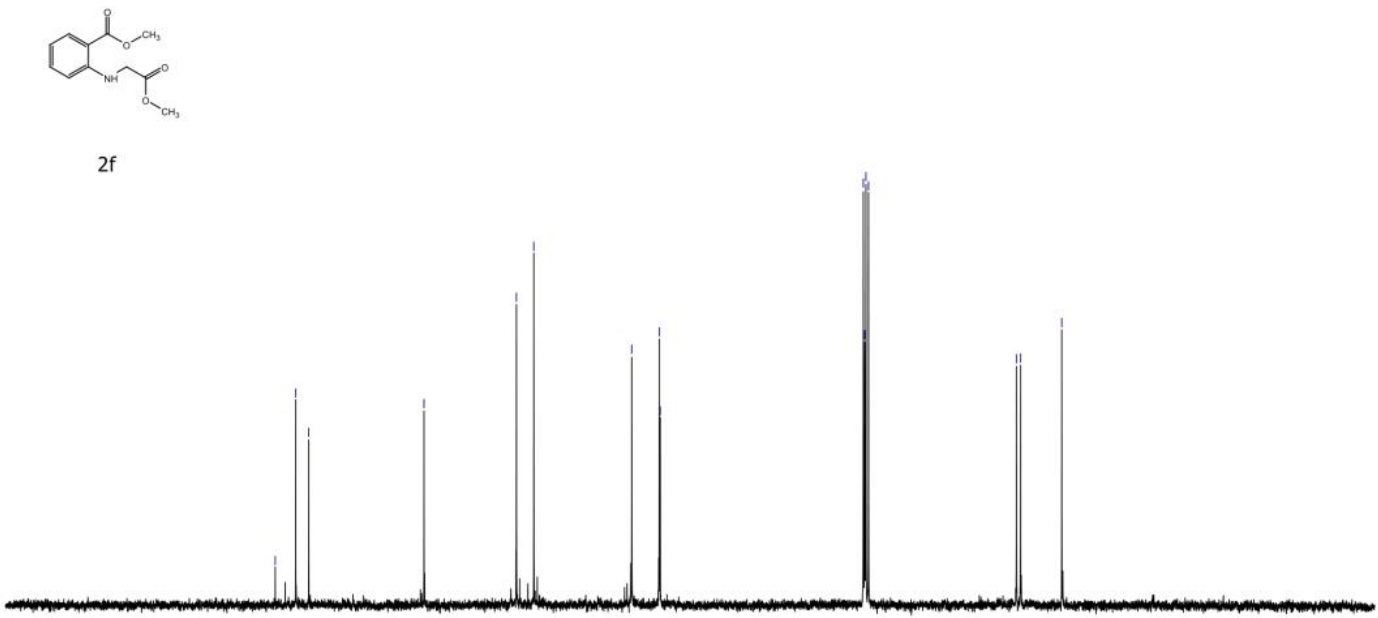

$\begin{array}{lllllllllllllllllllllllllllllllll}210 & 200 & 190 & 180 & 170 & 160 & 150 & 140 & 130 & 120 & 110 & 100 & 90 & 80 & 70 & 60 & 50 & 40 & 30 & 20 & 10 & 0\end{array}$ 
2

$4 a$
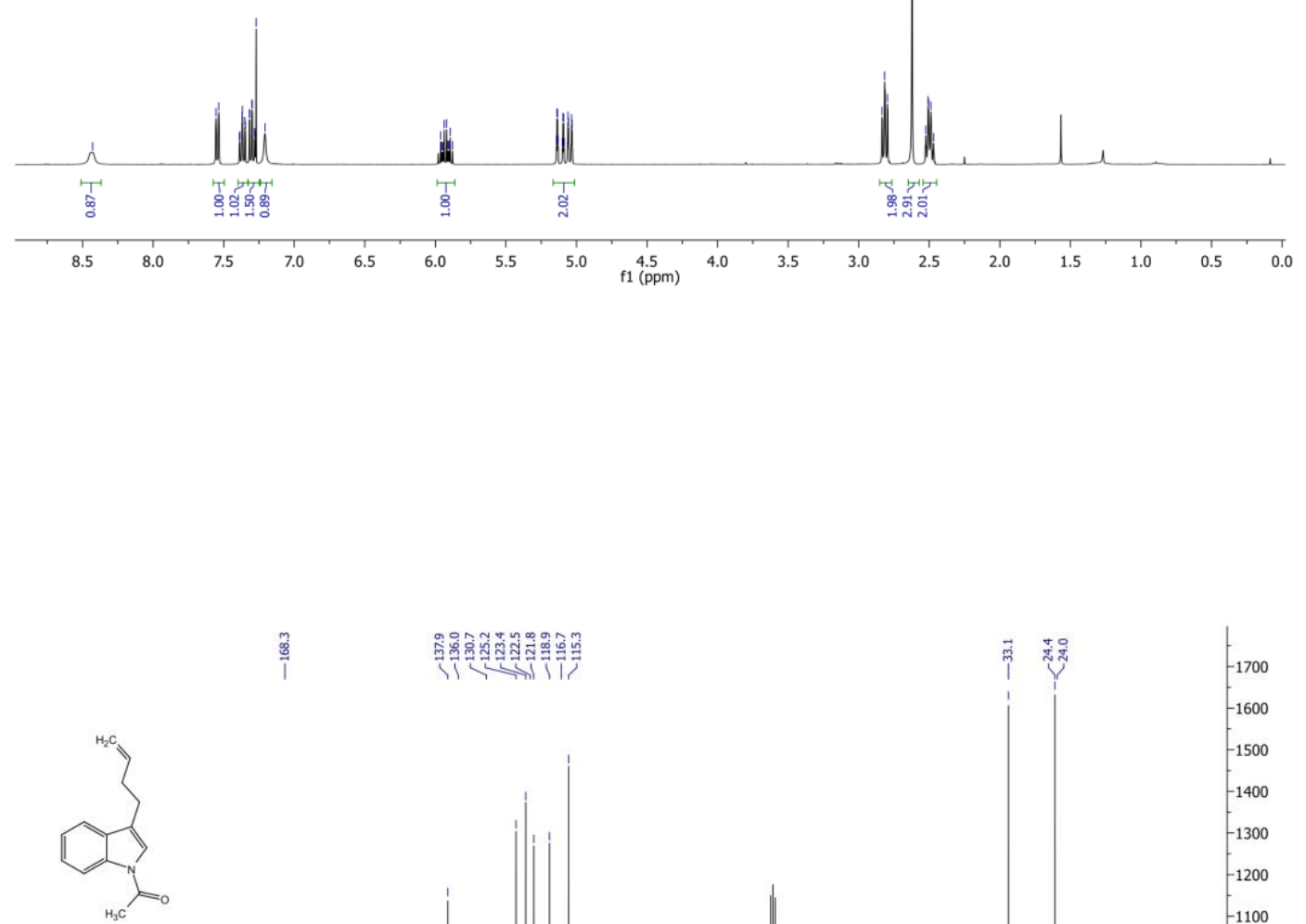

$4 a$

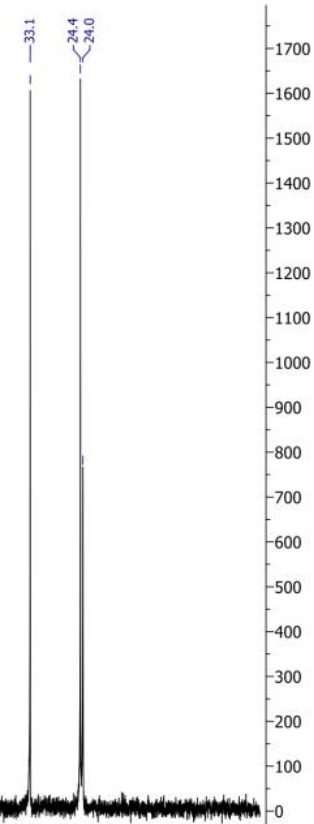

Ham. 


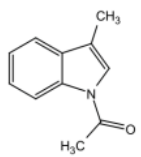

$4 b$

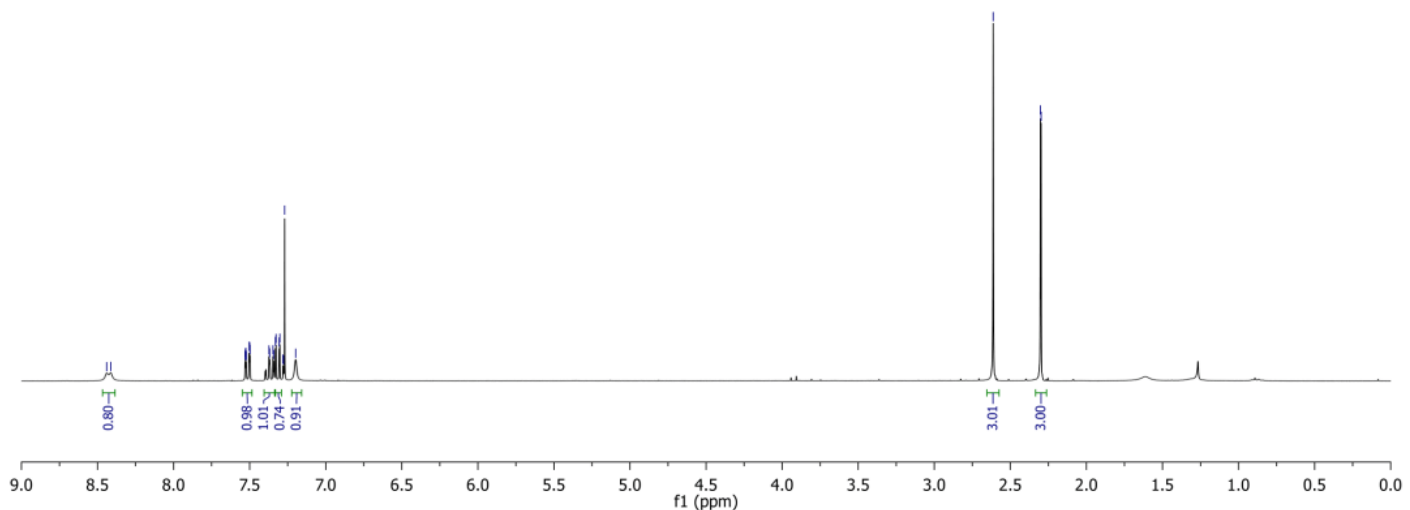

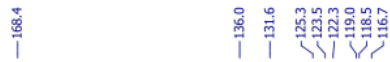

i $\quad \stackrel{\infty}{i}$

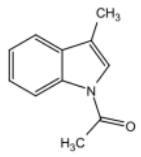

$4 b$
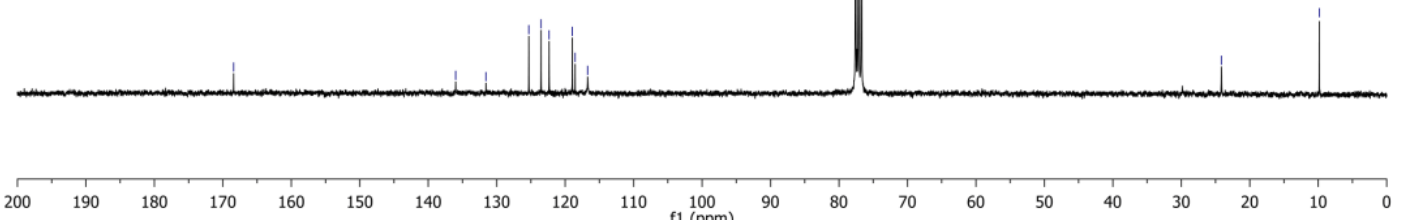


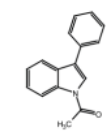

4c

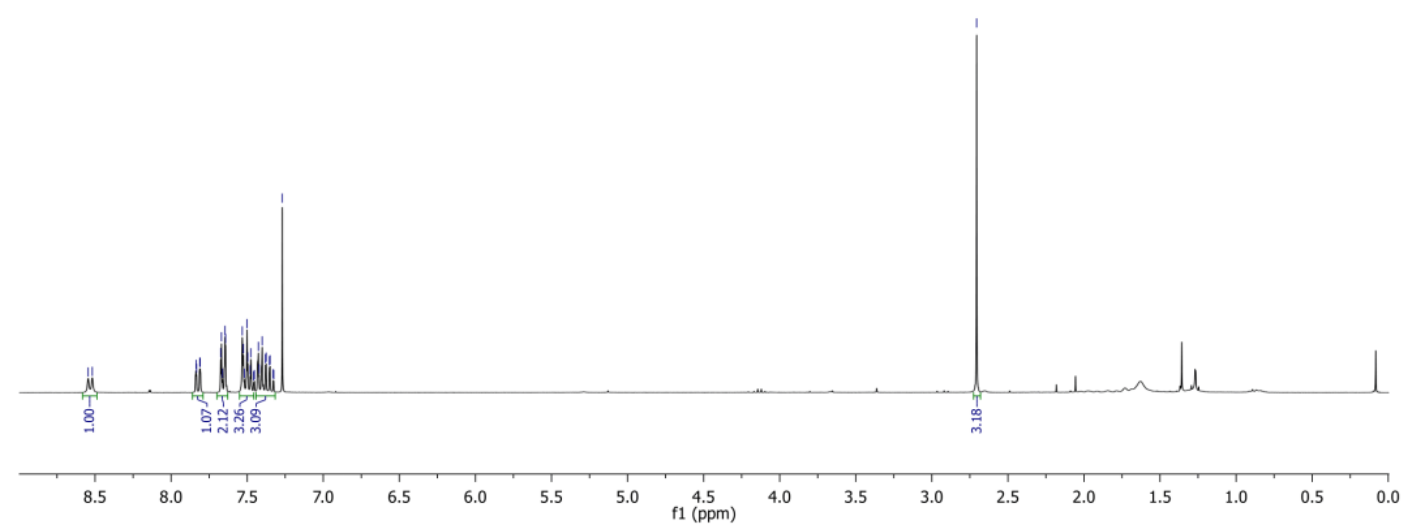

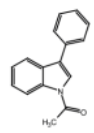

$4 c$
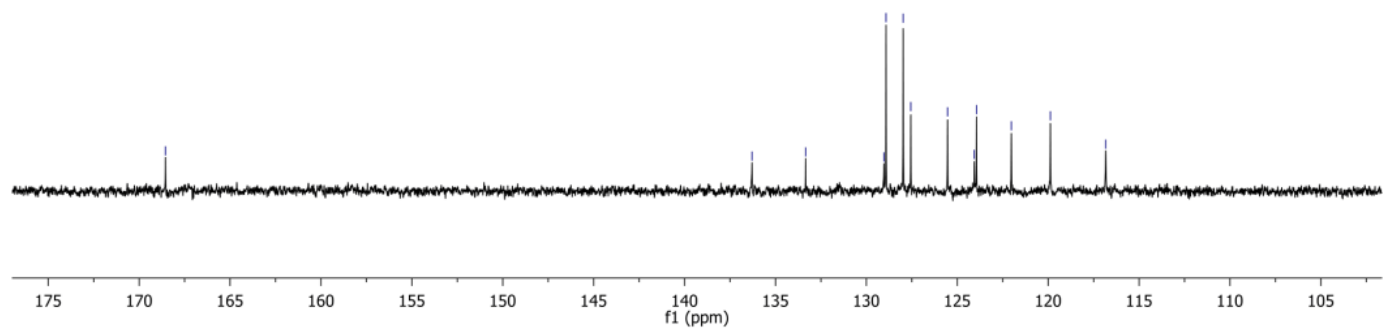

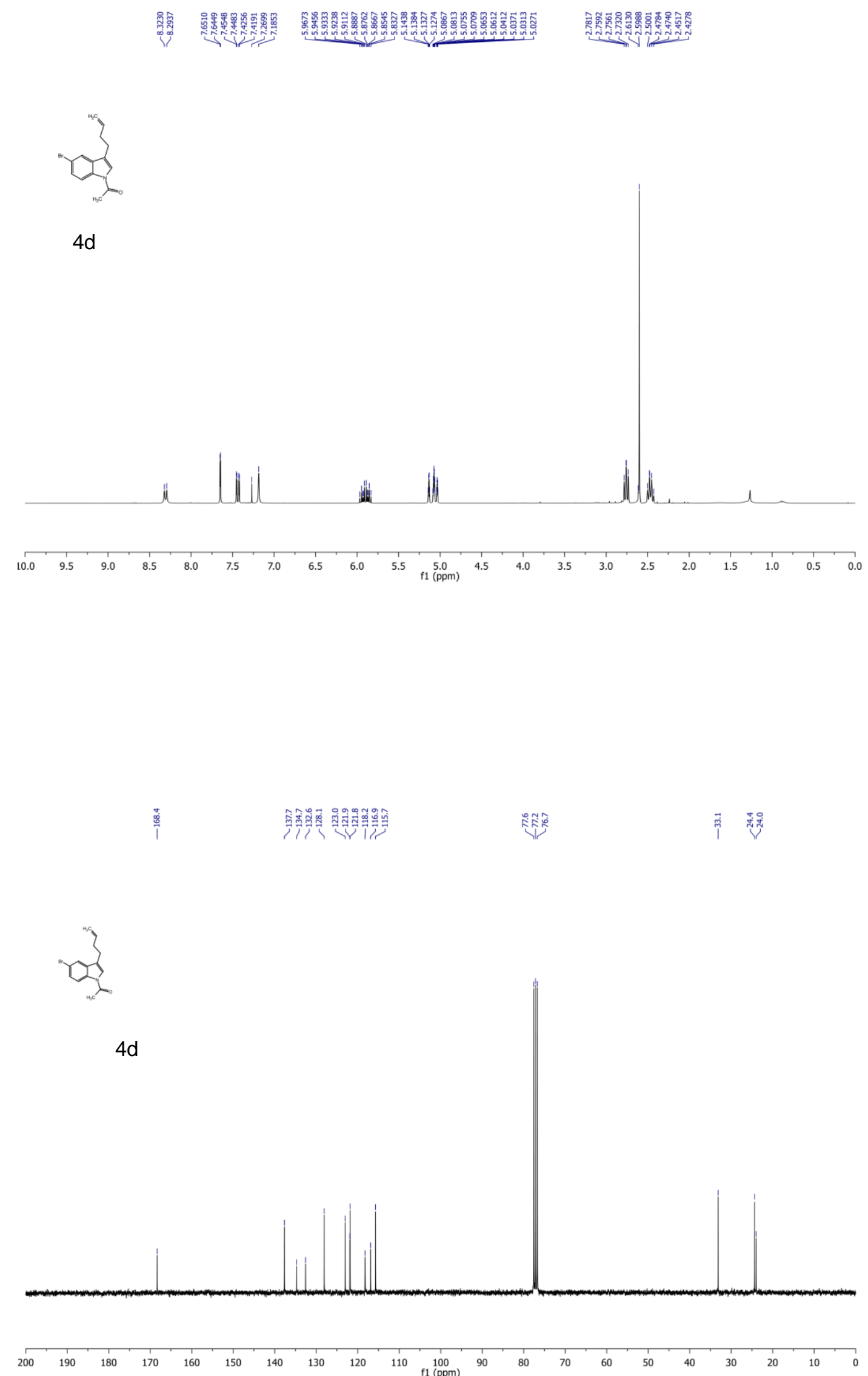

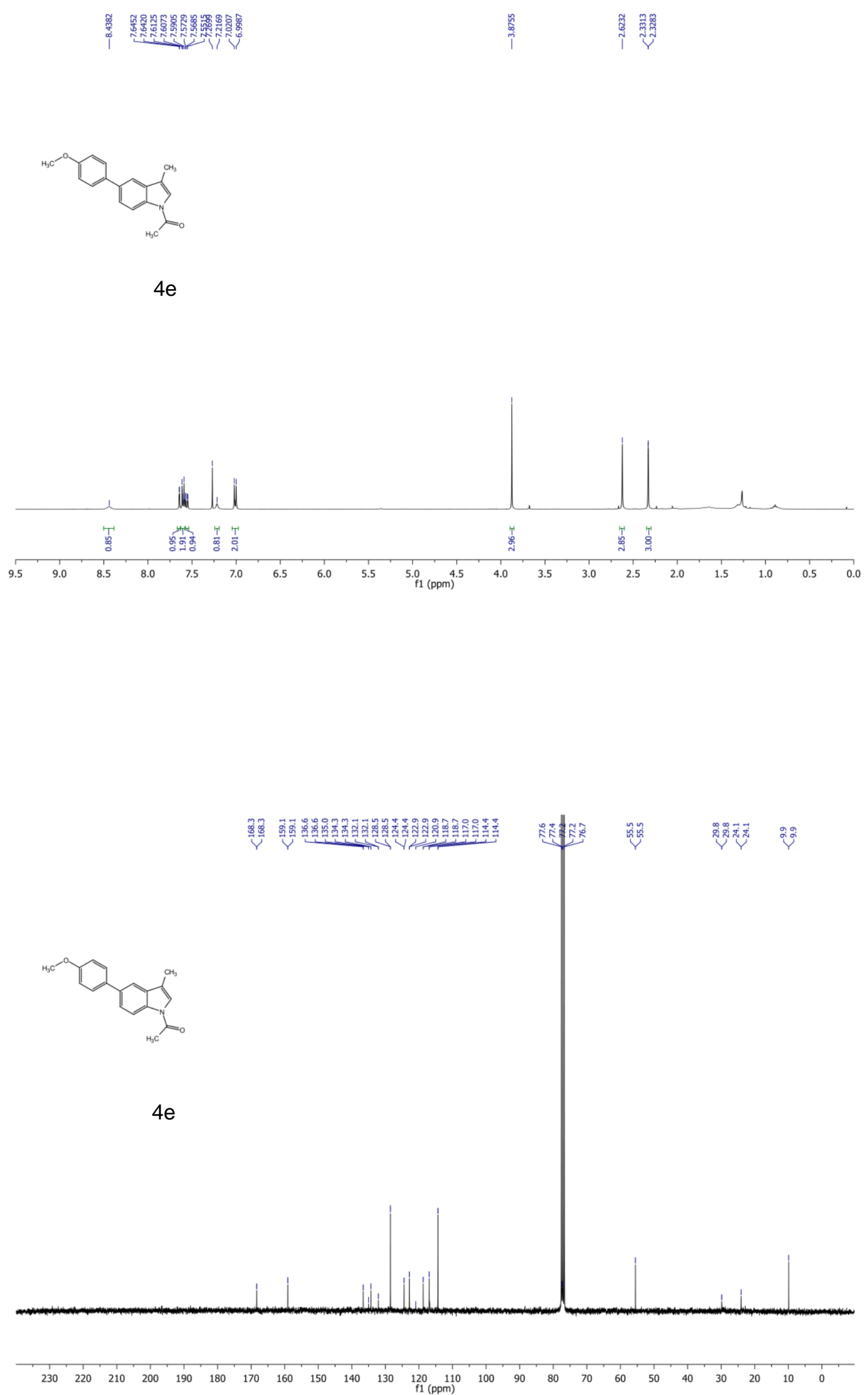


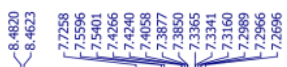

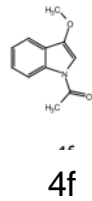

$4 f$

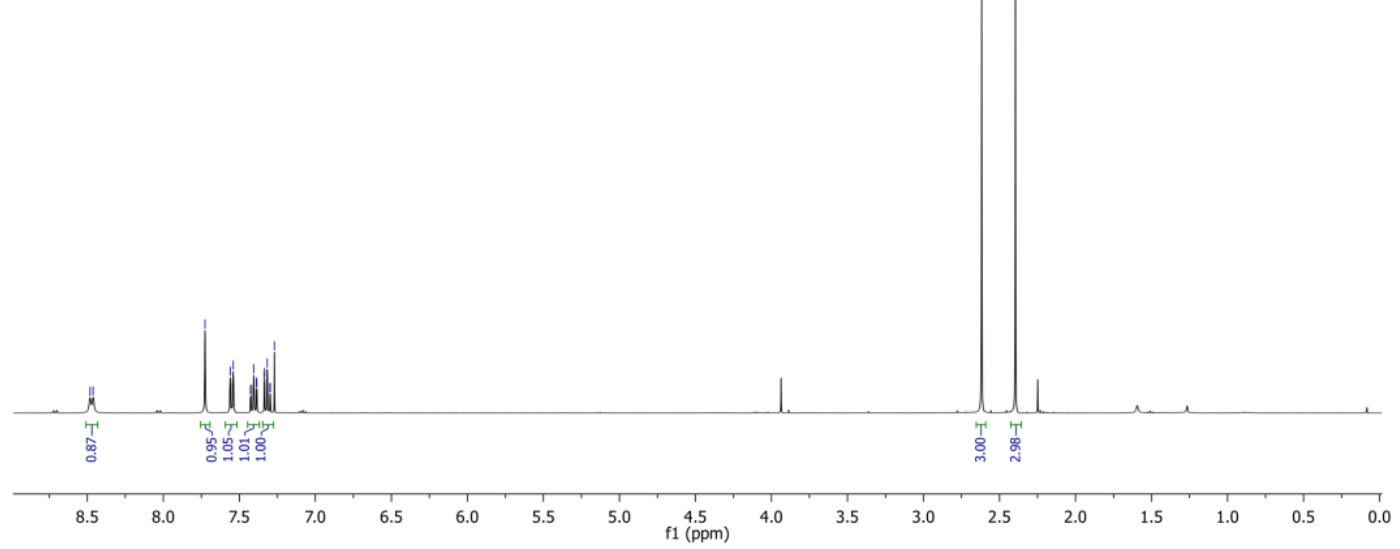

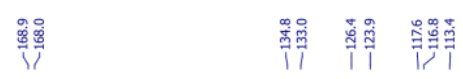

Q

$4 f$
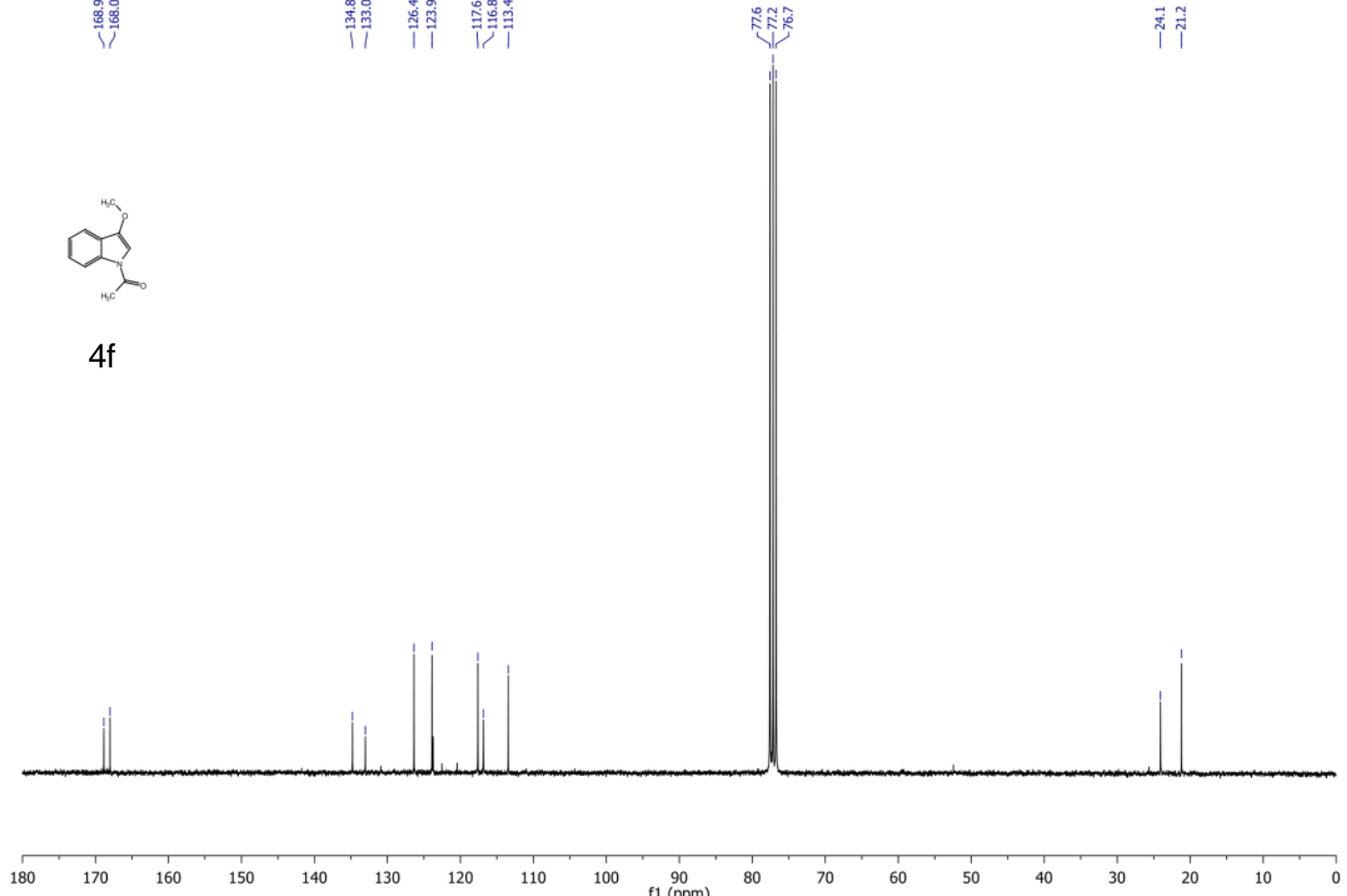


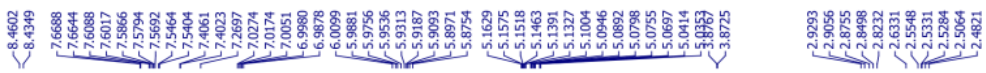

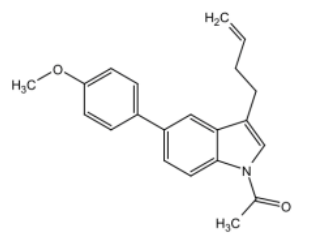

$4 \mathrm{~g}$
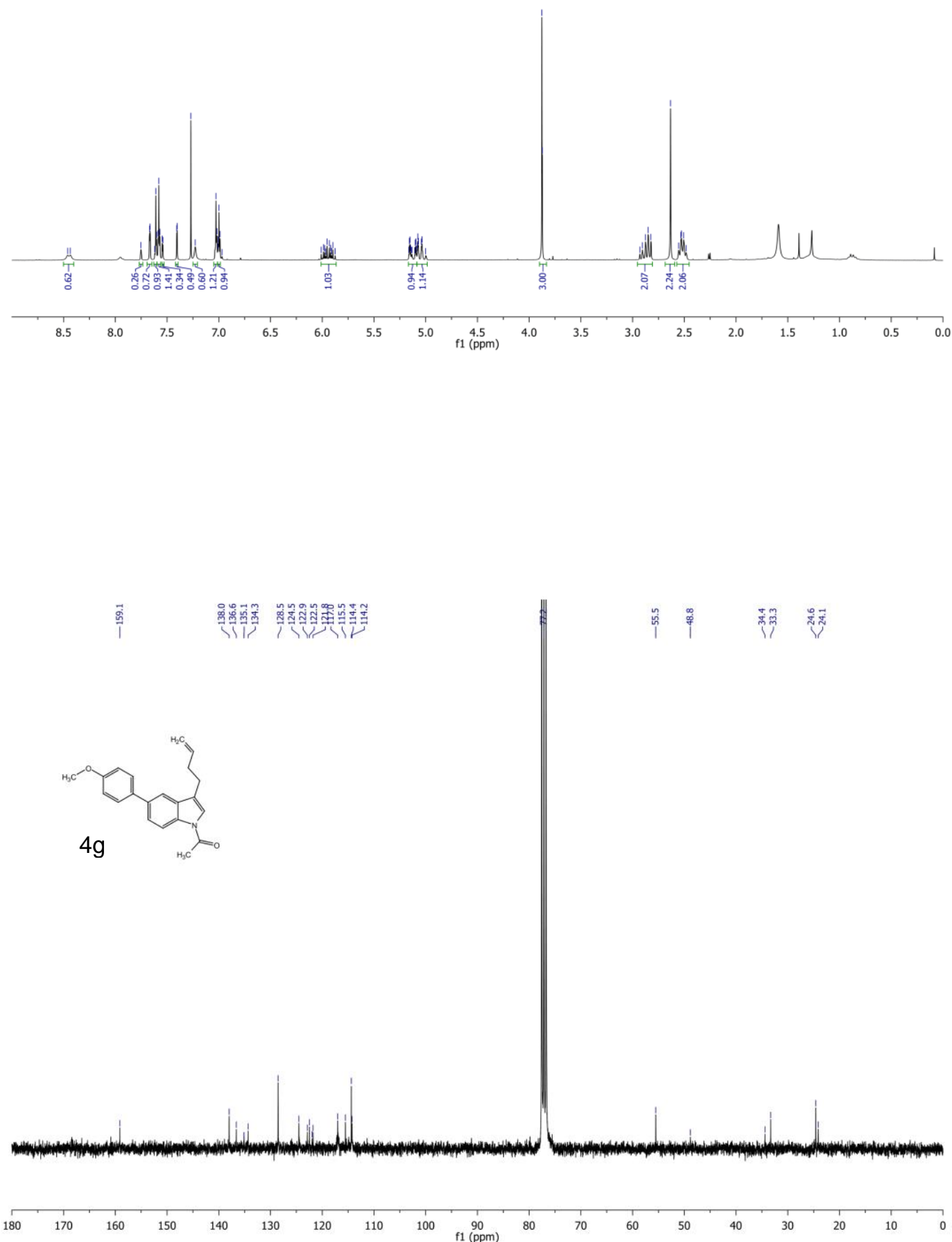


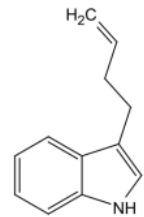

$5 a$
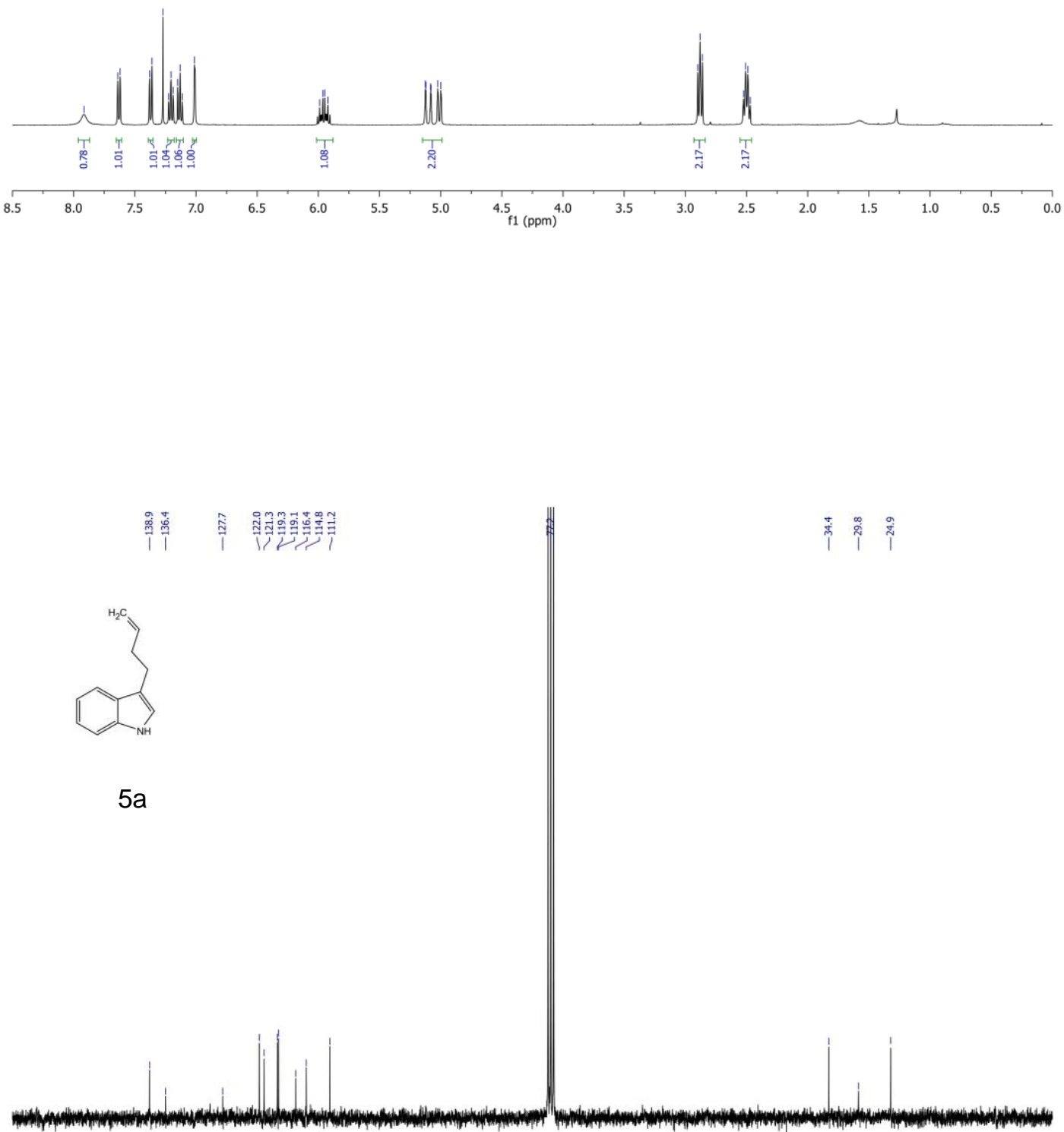

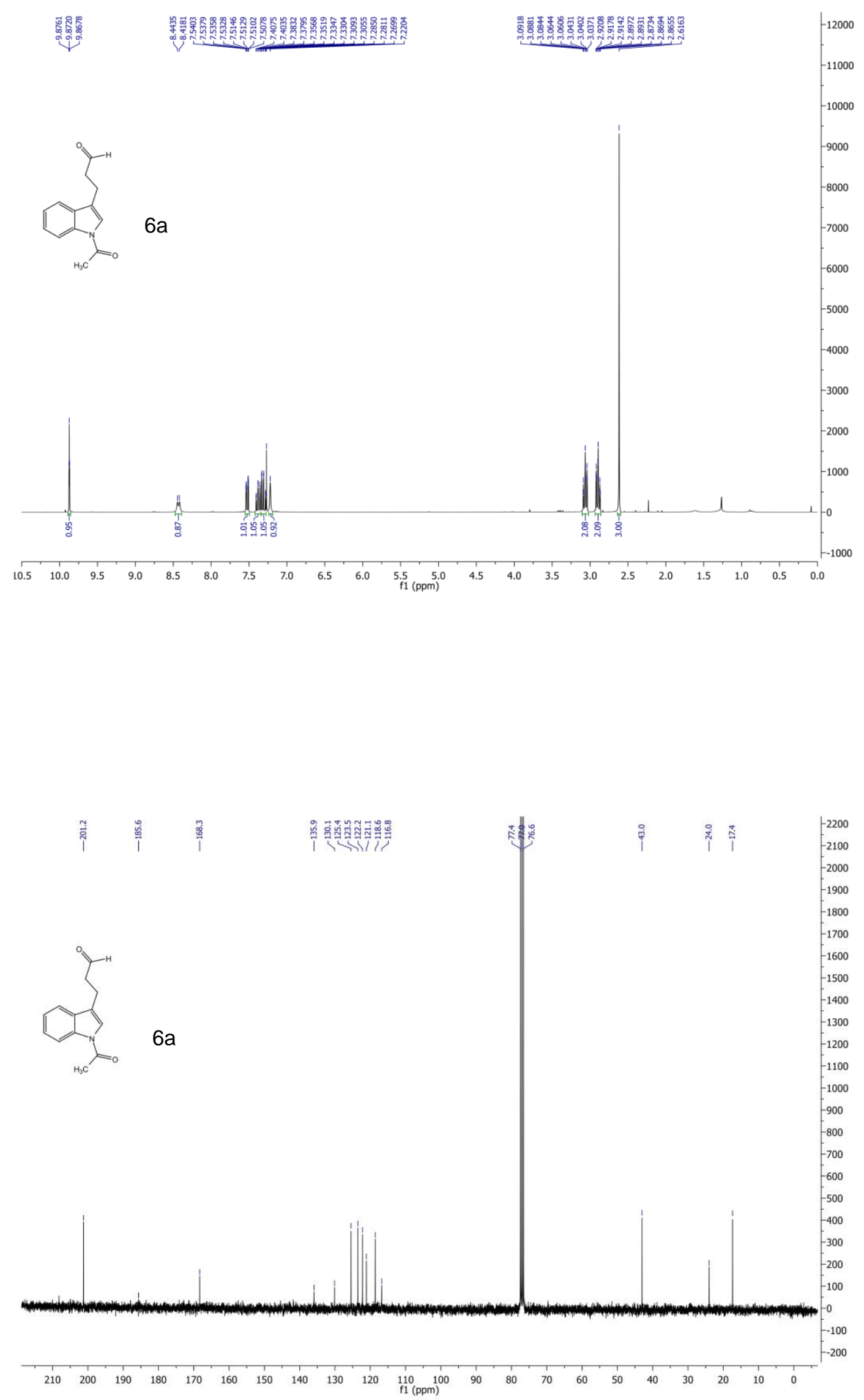

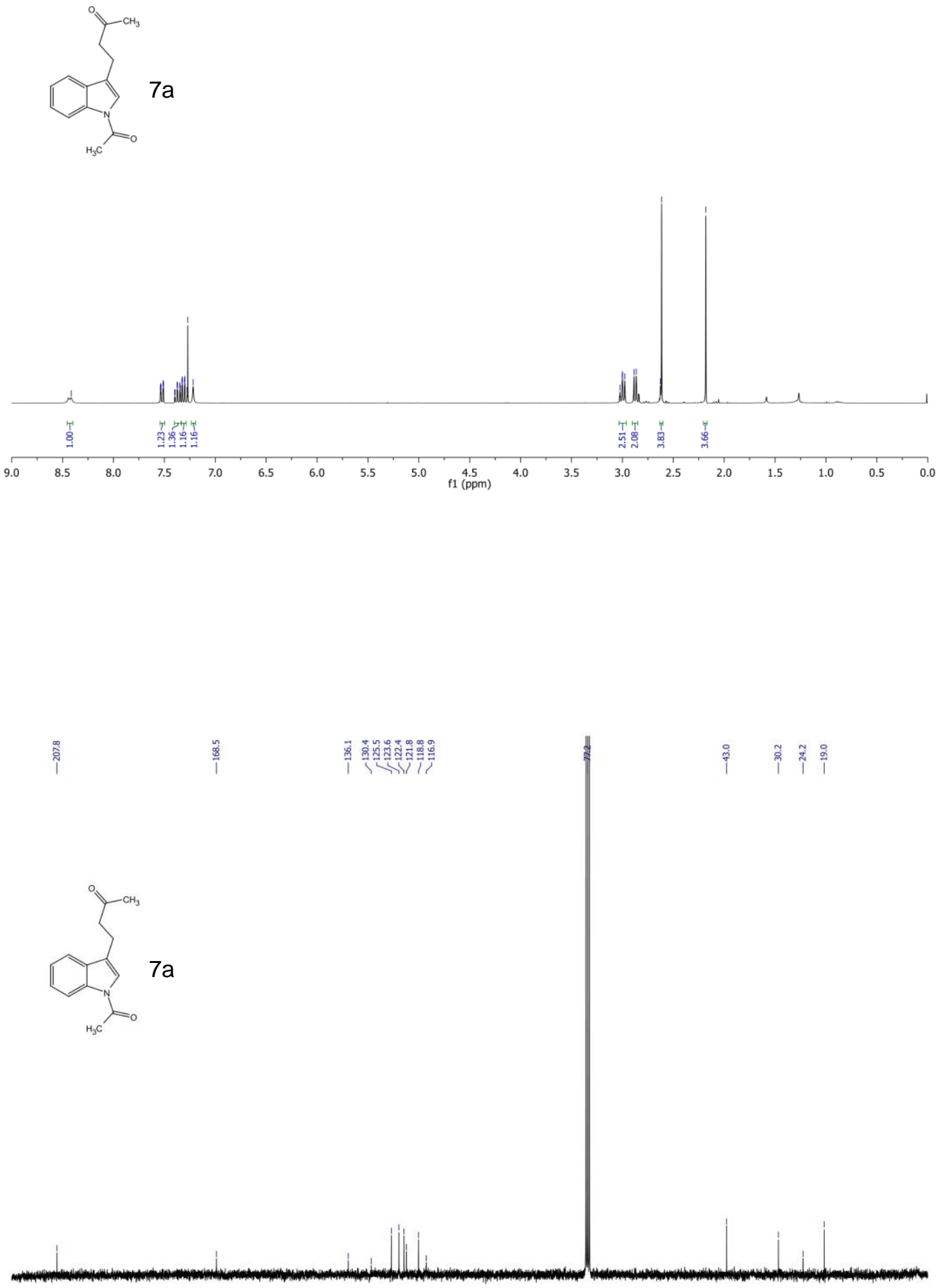

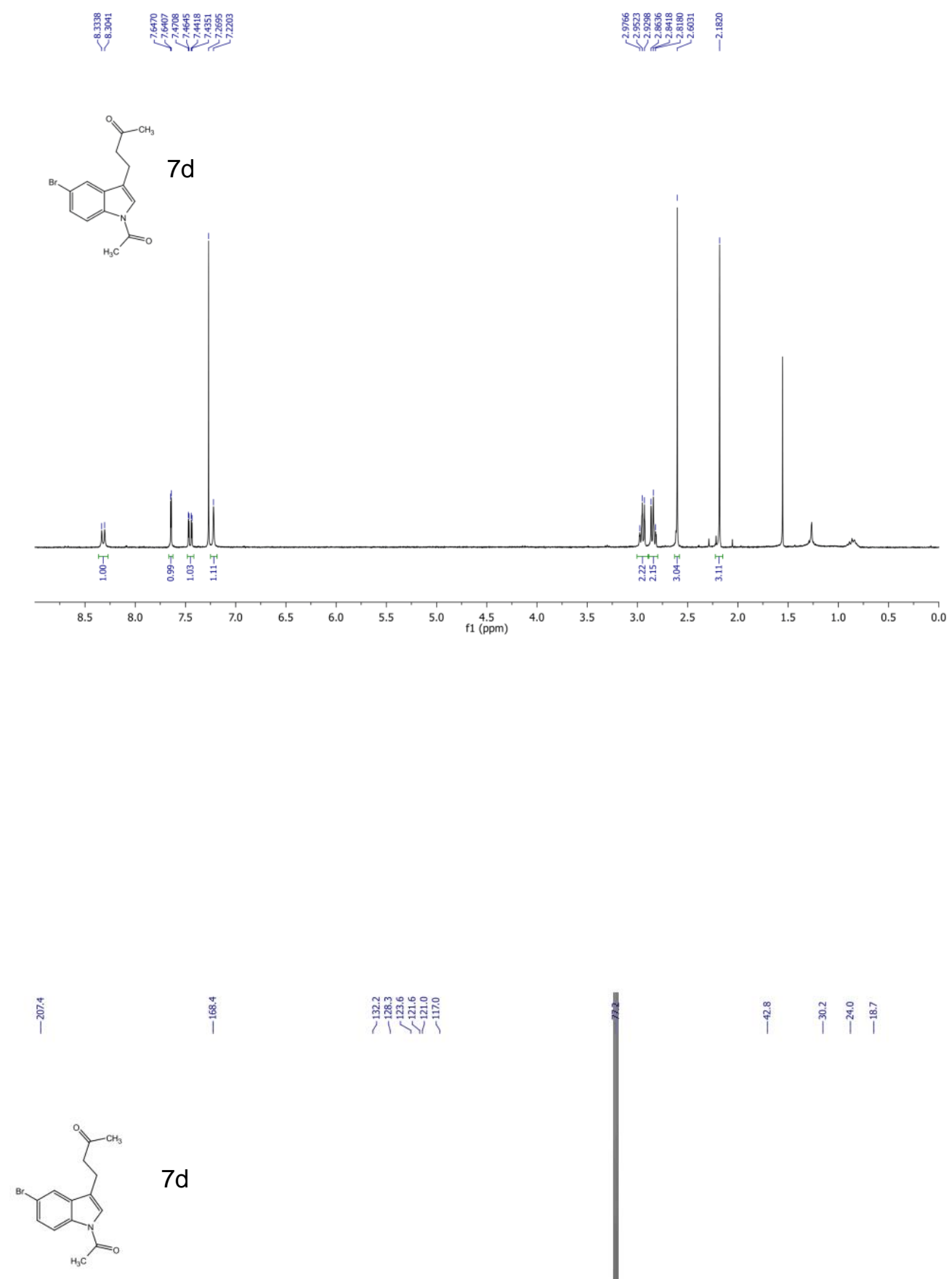

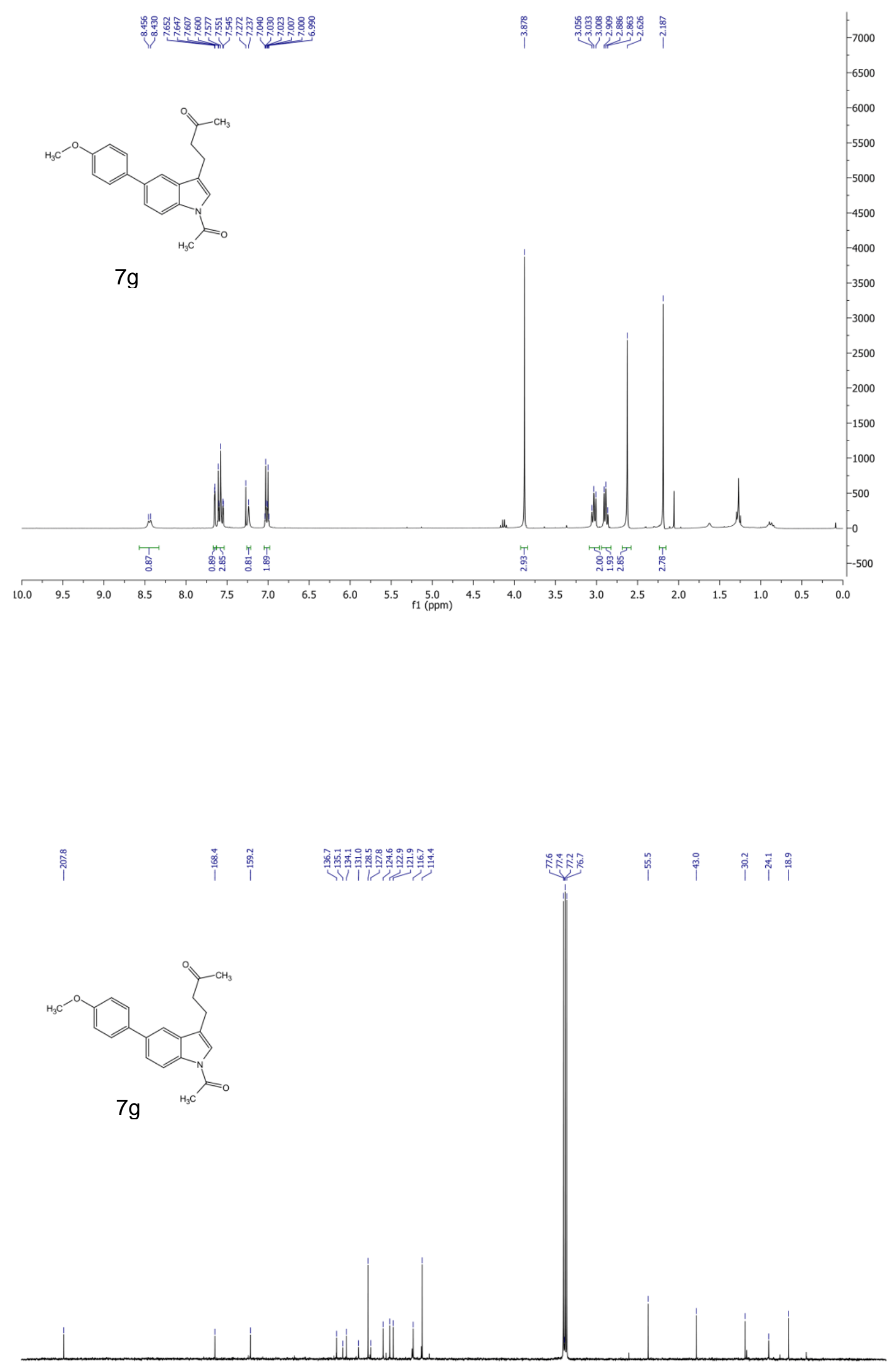

\begin{tabular}{|lllllllllllllllllllllllll}
1 & 1 & 200 & 190 & 180 & 170 & 160 & 150 & 140 & 130 & 120 & $\underset{\mathrm{f} 1(\mathrm{ppm})}{110}$ & 90 & 80 & 70 & 60 & 50 & 40 & 30 & 20 & 10 & 0
\end{tabular} 